\title{
El itinerario de la fe en San Agustín
}

\author{
(Semana Agustiniana en Pavía, 20-24 de Abril 1969)
}

Se esperaba. Y era un ansia que latía en todos los amantes de San Agustín. Si había un lugar en que podía renovarse lo agustiniano, éste no podía ser otro 'que Pavía. Aquí, en Pavía, se aunaba una tradición milenaria y un espíritu nuevo, una espiritualidad y un estudio. Ya el Papa Pablo VI, siendo Cardenal Montini había augurado esto y desde su Cátedra de Roma ha insistido una y otra vez en esta necesidad. Pavía y los Agustinos tenían una deuda con San Agustín y por fin se han decidido a salddarla. Su Excia. Mons. Antonio Angioni, obispo de Pavila, se ha hecho portavoz de estos deseos, ha nombrado un Comité organizador y ha iniciado nuevamente el agustinismo en Pavía. La unión entre todos, entre sacerdotes y Padres Agustinos y con la Universidad, se promete esperanzadora para los estudios agustinianos y para el buen éxito de estas Semanas de Estudio.

Una llamada a la reflexilón con San Agustín ha sido la tónica de la primera parte de esta iniciativa que llevaba por slogan "Pascua con San Agustín". Actos litúrgicos y homilías pretendían poner de relieve algún lado sobresaliente de su figura y doctrina. En agustiniano la ciencia precisa convertirse en vida, que se lincoa en el espíritu reflexivo y se revierte en la praxis de oada día, siendo una llamada más para una vivencia más íntima de sus valores.

El bautismo de Agustín.-La Semana Agustiniana se iniciaba el día 20 con la homilía, en el gran pontifical de la tarde, del Cardenal Giovanni Colombo, Arzobispo de Milán. Su tema central era el bautismo de San Agustín y consiIguientemente la parte que ha tenido Ambrosio en la conversión die Agustín, culminada en el último acto. El Purpurado explicó brevemente la noche pascual del bautismo con sus actos litúrgicos y los empeños a que somłrometía, la relación ide Ambrosio y Agustín en su ambiente cultural, examinando sus riquezas para 'Ambrosio en lo material también, para Agustín sobre todo en lo intelectual. Y luiego dirá: "No fue fácil a la gracia conquistar un tipo problemático y recalcitrante como Agustín. En esta empresa los aliados del Señor fueron Mónica en sus braciones y sus lágrimas ioon frecuencia despreciadas por el hijo, Ponticiano y Simpliciano y otros. Pero ciertamente el colaborador principal de Dios fue Am- 
brosio". Una vez convertido sería Ambrosio quien le administraría el bautismo. Sin embargo para la vida y la psicología de Agustín recordamos otro hecho que su Eminencia expone así: "Poco tiempo antes del bautismo halló la fuerza de dejar tornar al Africa, sola, la madre de su Adeodato, la innominada mujer cartaginesa, con quien había convivido dieciséis años. Si fue ciertamente Mónica quien la persuadiớ que era un obstáculo a los designios de Dios sobre Agustín y ni siquiera Mónica sabía cuán grandes eran- es probable que no haya sido ajeno 'Ambrosio, el predicador de la virginidad consagrada, al voto que aquella mujer hizo de no querer conocer más hombre alguno.

Fue también Ambrosio quien inyectó en el corazón de Agustín aquella duda, aquella insatisfacción y aquella turbación que, entre concesiones y represiones to inducirán a desafeccionarse de la profesión de docente y lo conducirán a la escena del huerto milanés, y luego al retiro de la villa de Verecundo a Casiciaco y por último al bautismo".

Quizá sea mucho conceder a Ambrosio en todo ello, pero es indudable que una parte no despreciable ha tenido en el viraje dado por Agustín a su vida. El Candenal Colombo, en la última parte de su homilía recuerda cuanto en lo doctrinal ha legado Ambrosio a Agustín, a saber la síntesis entre cristianismo y latinidad, la interpretación alegórica de la Sagrada Escritura y el ideal de la virginidad consagrada. Y añade, para dedicar su final a ello: "Y como en la pastorral de Ambrosio el sacramento de la fuente tenía una parte predominante, así 'Agustín quiso que fuese también en la propia pastoral". A este propósito expone con numerosos textos agustinianos la pastoral litúrgica y el compromiso que imfalica el bautismo. Como buen pastor le interesa primordialmente la vivencia de las exigencias del bautismo, extraída de los mismos textos de Agustín: "A la luz del pensamiento agustiniano aparece claramente que el bautismo es una regeneIración que, liberando al hombre del egoísmo soberbio del pecado, to hace nacer nuevo para una vidla nueva, en el humillde amor que impulsa al sacrificio de sí mismo por el bien y la alegría de los demás. No se puede, pues, contentar uno con ell rito exterior, sino que es necesario llegar a vivir la vida nueva que brota de aquel rito". Y luego de continuar las citas de los textos, concluirá con estas pralabras: "Lo que más le angustia es el olviddo del bautismo recibido, es la incoherencia de los cristianos frente a los emteños derivados del sacramento de la fuente. "Si has nacido en el bautismo, ¿dónde está tu vida nueva? Si has devenido fiel en el bautismo, ¿dónde está tu fe? Oigo tu nombre de bautizado, mas hazme ver' también tu Tealildad" (Serm. 228).

Era una buena inauguración, la conjugación perfecta de lo que debe ser lo agustiniano, bañado en el espíritu con exigencia constante de encarnación y traslurido únicamente en ella, llamando la encarnación a una vivencia más profunda. Podría decirse que el "itinerario de la fe" comenzaba con el bautismo, pero 
no es cierto, ni do fue para Agustín. A ello responderían las oonferencias en los días sucesivos.

El itinerario de La fe en SAn Agustín.-Ena el título general de la Sema. na Agustiniana, que desarrollarían diversos oradores y que en la organización lleivaría un ordien progresivo, que en el desenvolvimiento no se mantuvo por los empeños de los mismos oraldores. El programa preveía: "La experiencia del racionalismo maniqueo", "El influjo del espiritualismo neoplatónico", "Encuentro con San Ambrosio" y "Fe y vida en el pensamiento y en la experiencia de San Agustín". Todos los temas han tenido su desarrollo, aunque el onden fuera alterado.

El día 21 de abril tenía lugar la primera conferencia. Pero antes de iniciarla, se dio lectura a una carta del Papa Pablo VI, en la que se congratula de la iniciativa promovida por el Cardenal de Milán y el Obispo de Pavía, quienes le habían dirigido antes un mensaje breve para notificarle el acontecimiento. La carta 'del Papa decía así :

"Nos ha parecido muy digna de Nuestra aprobación y de nuestro aplauso la liniciativa, de la que Vid., Señor Cardenal, y el digno obispo de Pavía, Nosi habéis 'dado noticia particularizáda. Las dos Diócesis de Milán y de Pavía, en el reouerdo siempre vivo y conmovido de los santos Ambrosio y Agustín, de cuyos nombres reciben tanto lustre y honor, se han sentido concordemente unidas en el no. ble intento de preparar y actuar "Semanas Agustinianas".

De ésta la primera está para abrirse y, con oportuna y significativa elección, se iniciará en Pavía, en la Basílica de San Pietro in Ciel d'Oro y cabe el Almo Colegio Borromeo durante este mismo mes de Abril, en coincidenoia con la fiesta litúrgica de la conversión de San Agustín.

Al considerar las dircunstancias de tiempo y de lugar y la rica y sugestiva 'temática que, con meditado designio, será desarrollada en el docto convenio, Nos sonríe la esperanza, no falaz, sino cierta y firme, de que no solamente el éxito de la semana será provechoso, sino que obtendrá también vastas y fellides reperjcusiones.

En ella, sin duda, será iluminado con cuidada búsqueda histórica y profundo 'acumen psilcológico el misterioso camino, que llevó al Santo Obispo de Hipona de las aberraciones juveniles a la luminosa cima, por operaciones de la gracia divina y por próridas encuentros, entre los que fue decisivo el de San Ambrosio, del va'gabundeo intelectual y de las miserias morales a una gozosa posesión de la vendad plena, bondad y belleza y a una incomparable virtuld difusiva del mensaje cristiano.

Todo esto, valorado en su esencia, no es más quie un capítulo de la teología 'espiritual, nobilíisima disciplina que estudia las admirables vías del Espíritu Santo para purificar, iluminar e invitar las almas a uniones místicas con el Verbo divino.

Se Nos ofrece, pues, esta ocasión muy propicia para exhortar a cuantos se 
interesan de estudlios religiosos a que tengan en gran cuenta y cultiven con méto'do científico y apasionado empeño tal rama de la teología universal.

Junto a la teología especulativa, cuya importancia siempre será fundamental e insustituíble para la clarificación, integridad y defensa del dogma, ha de colocarse a nivel digno la teología espiritual, pues son muy válidas las razones que militan a favor de tal apreciación justa y debida. Ella, cuando es genuina en sus fuentes y en sus principios, múltiple y espléndida, sagrada por el contenido y por la for'ma, es la Revelación que penetra en la subjetividad humana, cúmulo de experiencias místicas, síntesis de naturaleza y gracia, fruto exquisito de catarsis y de sabiduría iluminadora, cuyo término no es, aunque sea supuesta en sus bases, la clairidad conceptual, sino la adoración, la plegaria, la efusión interior del espínitu, el 'silencio contemplativo, la vida.

Así la teología espinitual viene a integrar la teología dogmática, que por su ,cultivo se ha hecho más adornada, elevada y aplicadia. Las investigaciones, que le tocan en la vastedad de un plan sistemático bien dielineado y extenso, podrán constituir una aportación útil a la futura historila total de la teología espiritual, de la que dentro de la Iglesia se han dado y se pueden dar siempre nuevas y variadas expresiones, puesto que la plenitud del Logos, con férvida irradiación, tiende a desplegarse en siempre felices novedardes de progreso sin término.

Como San Agustín fue maestro y ejemplo incomparable de la teología espirritual, así será ciertamente estimulador y guía en la Semana dedicada a él cabe 'su Tumba gloriosa. El augurio que formamos para el fecundo éxito de las mismas Semanas, es que todos los participantes a ella y cuantos adherirán con deferente 'simpatía, o leerán las Actas sientan la necesidad de una alegre acción ide gracias 'a Dios por el impulso advertido hacia místicas ascensiones, ávidas de belleza y idescubridoras de verdad. "Tarde os amé, hermosura tan antigua y tan nueva, tartle 'os amé... —nos parece escuchar al mismo Agustín-. Y he aquí que Vos estabais dentro de mí, y yo de mí mismo estaba fuera... Vos llamasteis, gritasteis, derrumbasteis mi sordera; centelleasteis, resplandecisteis, ahuyentasteis mi ceguera; 'derramasteis vuestra fragancia, la inhalé en mi respiro y ya suspino por Vos; gusté, y tengo hambre y sed, me tocasteis, y encendíme en el deseo de vuestra paz" '(Confess. X, XXVII).

Con tal auspicio, que avaloramos con la oración, impartimos a $\mathrm{Vd}$., señor Cardenal, al celoso obispo de Pavía y a cuantos tomarán parte viva en la próvida empresa, o promoverán de algún modo sus desarrollos, propiciadora de copiosos idones celestiales, la Bendición Apostólica.

Del Vaticano, 7 de abril 1969. 
L'ras la lectura del texto tomó la palabra D. Casati para hacer la presentación del temario de la Semana y del orador de esta primera conferencia. Lo era el Padre José Morán, y tenia por tema: "La experiencia del racionalismo maniqueo". Hace un parangón entre el Agustín llegado a la madurez y a la responsabilidad y el mundo de hoy. Sólo cuando el hombre madura humanamente puede presentarse el problema religioso. $Y$ a la humanidad, dice el orador, hoy más madura que nunca, se le presenta agudamente el problema de su actitud religiosa. Examina la formación religiosa de Agustín en familia, su conciencia de culpabilidad y de pecado, su proclividad hacia la pasión para concluir a una fe tradioional, recibidcia, impuesta, no personalizante. A los 19 años Agustín se plantea el conflicto entre la fe y el problema moral que vive.

Se pregunta el porqué de su fe, busca y halla un modo acomodante y cómodo en el maniqueismo, en el que puede, al menos aparentemente, sentirse libre de responsabilidad y de culppa y contar con una especie de religión. Se le prometía razón y explicación de todo sin necesidad de autoridad ni de fe. Su inquietuid interior, sin embargo, continuó hurgándole en la propia intimidad.

Quiere verificar la verdad del maniqueismo, y lee, pregunta y llega a la conclusión siguiente: su doctrina no va de acuendo con ta ciencia de los libros, nadie sabe explicarle la doctrina y los problemas que implica, y ouando no tienen resIpuesta, se le manda y se le obliga a creer para comprender luego. Por otra parte, jél se siente pecadon y siente que es él mismo y no otro en él quien preca. Y se dice tristemente: Me han engañado. Esta dolorosa constatación y además el espitritualisma que comienza a insinuarse en su alma, le abren la vía al escepticismo y a la conversión. Su primer proceso hacia la madurez de la fe estaba conduído: desde una fe infantil hacia un racionalismo sin razones que le sume en el escep. joicismo y le descubre la necesidad de una fe, aún en lo humano. Es, empero, noble en su búsqueda y su nobleza le salvará y le madurará en la investigación y vejinificación de la verdad.

Agustín solamente pide al gunas virtudes humanas: una búsqueda sincera de la verdad, una inquietud, una nobleza die alma y de espíritu y buscar para encontrar y encontrar para seguir buscando. Con estos valores por delante la fe no tiene miedo a quien pide razones, a quien busca. $\mathrm{Y}$ hoy no debe tenerlo tampoco de inuestro tiempo, que se halla en período de verificación de sus creencias. Yo diría que firente a nuestro mundo la actitud que debe mantenerse es la de aquel obispo al que Mónica le pedía un coloquio con Agustín. El obispo, sabio e inteligente, no ha querido sostener esa entrevista con Agustín y él mismo alaba su conducta en las Confesiones, porque piensa que sin duda le hubiera vencido en sus razonamientos y hubiera seguido su camino. El obispo sabía que una cosa es el momento de la búsqueda y otra el momento del retorno y del encuentro. El hombre idebe convencerse por sí solo, debe preguntarse, buscar, estudiar y leer oon since- 
nidad. Cuando to haya verificado todo y lo haya experimentado todo, auando no tenga ya razones humanas ni científicas, y quede en el fondo de su corazón todavía la esperanza, pues hay que concondar en que ni las razones ni la cienoia son capaces de destruirla, sólo entonces florecerá de nuevo una fe profunda y arraigada. Podríamos condluir diciendo - finalizaba el orador- que el racionalismo de Agustín ha encontrado su razón en la fe. Porque el racionalismo, de hecho, cree en la razón y olvida que la razón no puede dar razón a sí misma. El creyente no es, pues, irracional, ya que el racionalista más puro cree.

El día 22, martes, desarrollaba su conferencia el Candenal Pellegrino, conocido ya en todos los estudios patrísticos y muy especialmente en los agustinianos. Su tema: "Fe y vida en el pensamiento y en la experiencia de San Agustim", y su exposición, la habitual en su estilo filológico y siempre positivo. Sólo una falsa untenpretación, comenzó diciendo, ha llegado a separar la fe y la vida, que en San Agustín, como ya en la Escritura, son plenamente inscindibles y quizá muichos de los problemas hoy existentes han nacido de esa separación quie, por otra ¿parte, no es auténtica. ¿Qué relación existe entre la fe y la vida? El argumento, idice el ilustre orador, podría ser afrontado de dos modos: o examinando el pensamiento, o haciendo el análisis de la experiencia agustiniana. En nuestra exposiIoión seguiremos una vía y otra, completando de este modo cuanto el tiempo breve de una conferencia lo permita.

¿De dónde brota la relación entre la fe y la vida en el pensamiento agisti'niano? Las fuentes para abordar el tema en Agustín son muy diversas y podría'mos limitarlas un poco, a la Escritura de modo especial, tratada por otra parte con la maestría teológioa que es habitual en el Obispo de Hipona, a su práctica pastoral, que no le ha permitido mantenerse sólo en la vía del pensamiento, a las ldiversas polémicas, pero plarticularmente a la polémica antipelagiana. Todas estas fuentes las ha asimilado nuestro autor en una meditación profunda y en un contacto con la palabra de Dios, antes y después de su conversión.

Haciendo culpable al tiempo que impione la limitaoión, el Cardenall Pellegri'no examina algunos momentos más sobresalientes del pensamiento de Agustín, recogiendo abundantemente los textos agustinianos. Hace un examen de las relaciones entre fe y vida, entrando directamente en su obrita precisamente sobre el argumento, à saber en el De fide et operibus del año 413, concluyendo con Agustín, tras un sondeo por toda la obra en la fe que obra por la carridad, ya que "'si fidelis caritas operatur, sine dubio bene operatur". En la relación entre fe y obras es preciso salvar siempre la iniciativa divina, ya que la fe es un don. La fe es, además, principio de renovación interior, es fundamento y raíz y es la justicia en sentido paulino. Más aún, la fe vendrá identificalda por el Santo en divversos lugartes con la vida divina. Fe y obras son dos caras de una misma realidad, que se prolonga, ya que la fe es algo vital. Se parte, claro está, de una fe verda- 
dera y profunda, manifestada en la vida, que no es un puro asentimiento intelec. tual. Es el testimonio de los hechos, ya contenido en el Evangelio y exhumado por Agustín con vigor: esto no es ninguna novedad que hoy se haya inventado El cristianismo ya desde sus fuentes más originales predicaba esto, aunque se olvide.

El valor de las obras no está en la apariencia, sino en la caridad, en el amor. El amor hace siempre el bien y así la fe obra por la caridad. La vida contemplativia -agregaba su Eminenoia- tiene en este sentido una justificación plena, jporque aún cuando se sufre por amor, esta meditación es el pensamiento de quien ama. Fe y caridad son también inseparables y el primado de la caridad aparece en las constataciones. Se pregunta al hombre no qué cree o qué espera, sino qué ama, ya que el amor define el ser y el obrar. Pero la fe está en nosotros, es Cristo quien está ien nosotros, y dadio que Cristo es la vida, no pueden separarse nunca fe $y$ vida en la doctrina agustiniana. Los textos agustinianos abundan a este respecto, sobre todo en sus sermones y homilías al pueblo.

En segundo término, el orador ha analizado la relación entre fe y vidh en la experiencia de Agustín, recorriendo cada una de las etapas de su itinerario hasta la conversión, ateniéndose especialmente a las Confesiones, obra por él tan conocida y tan usada en esta clase de argumentos. Pone de manifiesto la constante búsqueda de la verdadl y la lucha de Agustín haciendo frente a las pasiones —sensualidad y soberbia-, poniendo el acento sobre el Dios-verdad y sobre el hhombre-mentira. Ha conduido con un pasaje del lib. VII, 10, 16, que ha precisado 'así: Verdad y caridad, he aquí todo el oristianismo y he aquí el camino que nos mostró Agustín.

Todos estos pensamientos estaban jalonados en la conferencia del Emmo. Cardenal Pellegrino con textos agustinianos y ha brindado al auditorio una serena iy reposada lectura espiritual de textos agustinianos, internándose a veces por los problemas que agitan nuestro tilempo, aunque sin querer entrar decididamente en ellos.

El profesor Michele Federico Sciacca era el orador del día 23 y su tema era en su título una garantía plara el orador: Influjo del espiritualismo neoplatónico. San Agustín es, para ell orador, un filósofo que ha unido pensamiento y vida y 'de ahí le brota por reflexión y pensamiento su contemporaneidad. Aun en el argumento que desarrollará podra verse en su mediida la actualidad del filósofo Agustín, fuente de pensamiento y de reflexión para hoy. Agustín, decía el orador, tha encontraldo a los neoplatónicos, cuando no era ya maniqueo, pero no siendo 'católico todavía. En este momento, el prof'esor Sciacca se entretiene en deoir que 'algunos han pensado que Agustín se ha convertido al neoplatonismo puro y otros que su conversión es posterior, coincidiendo con el episodio del huerto de Milán. En el momento de la lectura de los libros de los platónicos de que habla Agustín y que el orador centra especialmente en Plotino, el joven de Tagaste ha cristiani- 
zado el neoplatonismo, no ha platonizado el cristianismo. Su tesis girará en torno a este punto e intentará grabarla en los oídos y en las mentes de los oyentes.

A este fin agrega que en ese encuentro Agustín tenía dos clases de dudias: una tealógica, dado que no podía concebir la espiritualidad de Dios, y otra filo'sófica, que ena el onigen del mal, que segun el maniqueismo procedía diel principio del mal. Sin duda las Enéadias de Plotino, algo de Porfirio y de Platón, tal vez el Timeo, le ayudaron en ese doble sentido. Esa lectura y los sermones de Ambrosio que escuchaba todos los domingos en la Iglesia colaboraron a la solución de esas dudas: Dios es la verdad y la luz inconpórea y el mal es la privación del bien, es la deficiencia del ser, que solamente pueden darse en el bien o en el ser.

La solución sería solamente sobre un plano fillosófico, ya que los neoplatónijos no le resolvieron las dudas teológicas. Estas le vendrían disipadas por el Evangelio de San Juan y las cartas de San Pablo. Le enseñaron la encarnación del Logos con su humillación, que era lo inconcebible para los neoplatónicos y de los que Agustín no podía esperar respuesta. Con la lectura, por tanto, dirá el profesor Sciacca, de los neoplatónicos Agustín no neoplatoniza el cristianismo, sino que oristianiza el neoplatonismo, es decir lee los neoplatónicos con ojos cristianos a través del Evangelio de S. Juan, intenpretanido los textos 'de aquellos con las ideas reoogildas sea en los Sermones del obispo de Milán, sea en la lectura de las Escrituras, en especial de los textos a que antes aludíamos. Es esto tan verdaad que no retilene cuanto los neoplatónicos le enseñan, sino que recoge de ellos lo positivo y aprovechable y lo integra a un concepto netamente cristiano. Acepta la idea de Dios como luz incorpórea, pero la completa, dicien'do que esa luz se entiende con el amor, que sería el entendimiento de amor, de Dante. Acepta la idea del mal como defecto de bien y de ser, pero la completa con la idea cristiana de creación, que corta radilcalmente el camino a todo dualismo de onigen, es decir a la teoría de un doble principio.

El autor concluye, como se ha hecho en todos estos días, con una aplicación a nuestro mundo actual: como Agustín ha oristianizado el neoplatonismo y la cultura de su tiempo y Tomás de Aquino ha cristianizado el aristotelismo reinante del suyo, así nosotros tenemos que hacer frente a la cultura del nuestro que trata ide "deshelenizar" y de "desromanizar" con peligro de dejarlo todo en un puro thumanismo, y cristianizarla, a ejemplo de los grandes del pensamiento pasado. 'La tesis del profesor Sciacca, sobre todo si se tiene en cuenta la evolución agustiniana del principio, sería discutible y lo es y to tha sido de thecho y las textos 'de las mismas Confesiones, estudiados en la distinción del tunc y del nunc, nos lo |probarían con precisión, pero tiene el docto filósofo italiano la facilidiad de patentizanla ante un público susceptible de asumirla.

Finalizaría la semana el día 24. Por la mañana la función litúrgica tendría 
su centro en la Basílica de San Pietro in Ciel d'Oro, oficiada por Su Excelencia Monseñor Antonio Angioni, al que se unían en la concelebración sacendotes de Lla diócesis y un nutrido grupo de Padres Agustinos, entre los cuales figuraba el M. R. P. Asistente, Quacquarelli y el Provincial de la Provincia Ligure, P. Bonassi. 'Así se mantenía la fidelidad al programa trazado inicialmente en esa colaboración en el trabajo y entre el espíritu y el estudio de lo agustiniano. Por la tande 'aoupaba la cátedra el profesor Pizzolato con una conferencia, cuyo título era: Encwentro con S. Ambrosio. Recordando el encuentro con Fausto, hace luego un panangón entre Ambrosio y Fausto, poniendo de relieve las diversas cualidades de uno y otro y la impresión causada en Agustín. En las Confesiones aparece en claro ese doble, en el vendedor de palabras, sin soluciones, y el hombre de "suavitas" de estilo y sobre todo de aocesibilidad a la Escritura, haciéndola más agra'dable y manteniéndola en la autoridad que le conviene, ayudándole por otra parte a resolver algunas de aquellas dudas que le habían angustiado antes.

El gran valor de Ambrosio en Agustín ha consistido en el devolverle aquella confianza en la autoridad que había perdido en los maniqueos y por la que había seguido luchando. El sentido de la búsqueda de la verdad le viene agudizado y se enciende nuevamente con la lealtad y nobleza de aquella alma señorial. En realidad, dirá el profesor Pizzolato, Agustín no buscaba soluciones teóricas, buscaba sobre todo una persona en quien confiar, que le volviese al sentido de la autoridad no por imposición, sino por valer. Y lo ha encontrado en Ambrosio. Además Ambrosio le ofrece un nuevo modo de buscar fundado en la meditación y en la Escritura con una interpretación alegórica de la misma.

A este propósito, recuerda que a la acción oculta, pero eficaz de Ambrosio se añadía la labor del círculo neoplatónico milanés, cuya doctrina venía envuelta 'en el oristianismo y se la ofrecía el mismo Ambrosio en sus exposiciones y ser'mones. El orador ppiensa que no hay que confundir las dos acciones y que además iel influjo de Ambrosio ha sido superior y que a él se debe si Agustín no se ha pparaido en el neoplatonismo. El exégeta convencido y sabio ha dado al Hiponense unos horizontes que no había sospechado y le ha ayudado a surperar las dificultades que tenía planteadas en el curso del neoplatonismo. De hecho el texto paulino de la escena del huerto fue interpretado por Agustín según los cánones de la exégesis ambrosiana.

No obstante, no ha dejado el profesor Pizzolato de señalar que los contactos personales entre los dos grandes de la Iglesia fueron escasos y hasta fríos. Pero Ifue un contacto superior de espínitu, en el que Ambrosio hacía trasparecer a Dios thumilide, pero eficazmente. En la conversión de Agustín, concluiría el orador, Ambrosio fue el instrumento poco brillante, pero determinante. El mismo Obispo de Hipona no dudará en llamarlo "padre".

Esta primera Semana Agustiniana en Pavía era un éxito en todos los senti- 
dos, en onganización, en conferencias, y en asistencia de público, distinguido y siempre atento. Ha respondido la Universidad con sus profesores y sus estudiantes y han respondido todas las personas más directamente interesadas en la historia espiritual del cristianismo y en los problemas humanos que la historia de Agustín suscita. A todos ellos se debe agradecer el que haya vuelto la tradición agustiniana a florecer en la ciudad de San Agustín y de Boecio, y el que se realice con frescura sin verano. Ahora solamente nos queda esperar la publicación de las Actas en las que se podrá apreciar la altura y competencia de los conferenciantes, y la onganización periódica de encuentros de este nivel para que San Agustín continúe irradiando su luz desde su tumba y poldamos convencernos de que San Agustín aún no ha muerto. Y no ha muerto porque ha habido hombres entregados a exhumar para hoy desde Pavía su recuerdo, en las personas activas y bien preparadas de D. Casati y del P. Scanavino, verdaderos promotores de la Semana, en representación y por delegación de su Excelencia Monseñor Antonio Angioni que con tanto cariño ha tomado estas celebraciones.

J. MORÁN

Pavia-Valladolid 